\title{
Analysis of water consumption of a drip irrigation system compared with sprinkler installation: a case study in Sicily (Italy)
}

\author{
M. L. Deangelis \& G. Negrini \\ Dipartimento di Scienze Agrarie e Ambientali, \\ Universita' di Milano, Italy
}

\begin{abstract}
The techniques used for water supply for the crops are many and each has unique characteristics. For all methods it is of prime importance to pay attention to the efficiency of water use, which is increasingly subject to high waste.

Therefore, it seems essential to investigate the issues surrounding water management and efficiency of its distribution techniques for cultivation. In particular, in this work, we will analyze the relationships between water resources and crops, as these can change with variations in soil properties, weather factors and how they are influenced by irrigation management.

In this regard, a citrus grove located in the Sicilian province of Catania was chosen, on the slopes of Etna, whose characteristics reflect the standard of local citrus groves surrounding the volcano.

The two main irrigation methods that were used in the plot are compared: the first plant, by sprinkling, was active from 1965 to 2008. Given the high costs of maintenance, water supply and decreasing production yield, it was decided to replace it with a more modern system of subirrigation, which became operational in 2009.

In order to compare the two different installations, technical properties of the plants and their water consumption are considered. This study highlights what are the aspects to be considered in optimizing the water use efficiency. Keywords: sprinkler irrigation, drip irrigation, water consumption.
\end{abstract}




\section{Introduction}

The techniques used for crop water supply are many and each has unique characteristics. For all methods is of prime importance to pay attention to the efficiency of water use, which is increasingly subject to high losses.

Therefore it seems essential to investigate issues concerning water management and efficiency of its distribution techniques for cultivation. In particular, in this work, we will analyze the relationship between water resources and crops, as these may change with variations in soil properties, kind of crop and weather factors and how they are influenced by irrigation management [1$3]$.

As an object of evaluation a citrus grove was chosen, located in the Sicilian province of Catania, on the slopes of Etna, whose characteristics reflect the standard of local citrus groves surrounding the volcano (Figure 1).

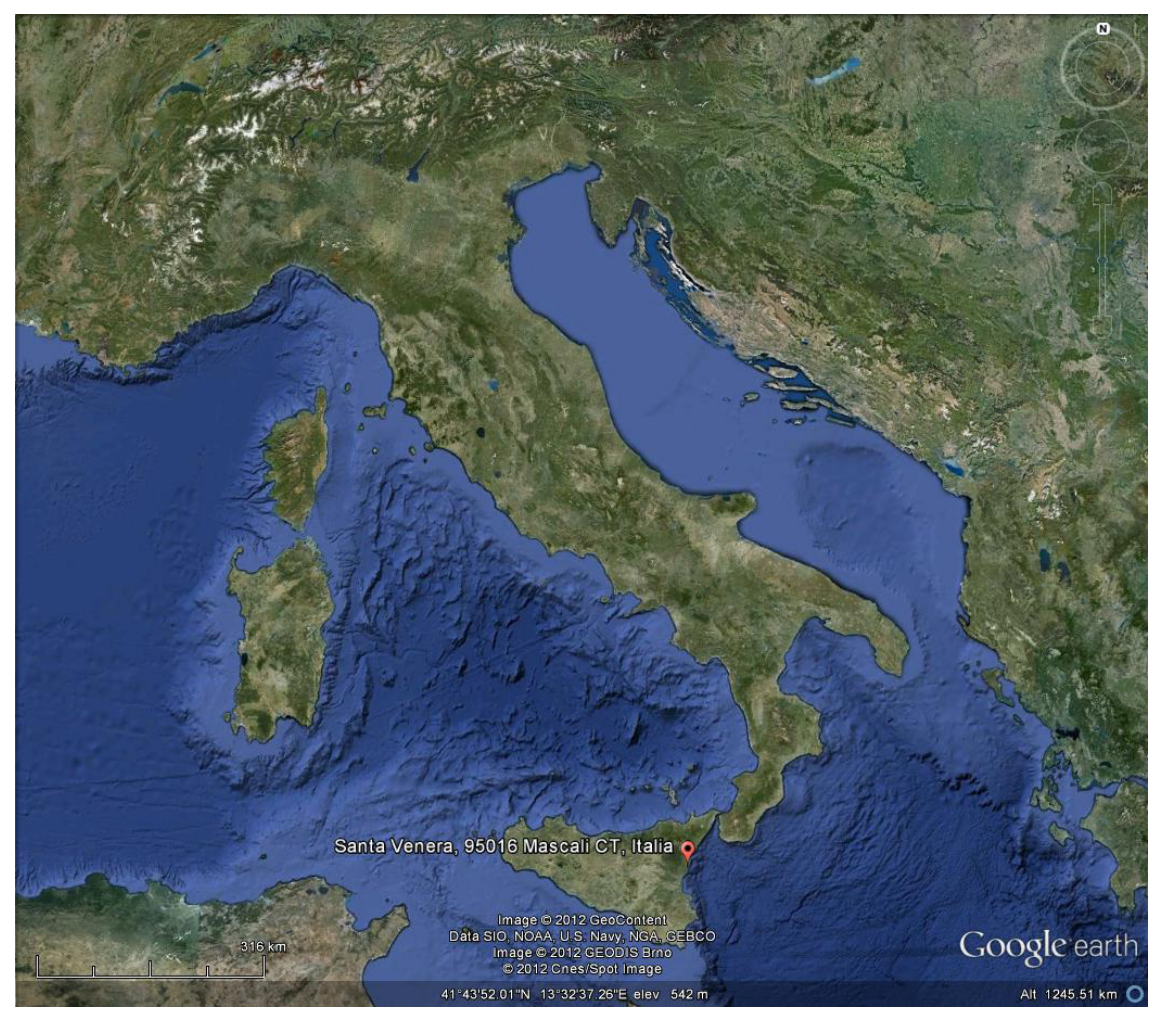

Figure 1: Location of Santa Venera, near the Etna volcano in Sicily (Italy).

Two main methods of irrigation which involved the plot are compared: the first system, sprinkler, was active from 1965 to 2008. Due to high costs of maintenance, water supply and decreasing production yield it was decided to 
replace it with a more modern subirrigation system, which became operational in 2009.

In order to compare the two different installations, their technical properties are highlighted: components, materials and their water consumption. Through the analysis come to light the aspects to consider for optimization of water use efficiency.

\section{Sprinkler irrigation system}

In its original setting (1965-1976) the system was composed of 6 independent sectors, each of which equipped with 13/14 sprinklers for a total of 80. Each field covered an area of approximately 6660 square meters, with a flow rate of $6.6 \mathrm{~s}^{-1}$, equivalent to an intensity of $3.5 \mathrm{~mm}$ of rain per hour (nearly $25 \mathrm{~mm}$ in 7 hours of daily operation).

These values are believed to be sufficient for efficient irrigation of the citrus grove. The plant was powered by an electric pump with a flow rate of $6.61 \mathrm{~s}^{-1}$ and the prevalence of $55 \mathrm{~m}$. The pump was connected to two existing reservoirs whose capacity is 131 and $750 \mathrm{mc}$ respectively, placed at a height slightly higher, so that the water flows by gravity to the pump.

In 1976 it was designed the expansion of the existing plant irrigation to further 2 acres, divided into 4 sectors. The flow rate of the new plant was $6.47 \mathrm{~s}^{-1}$, with an intensity of $3.5 \mathrm{~mm}$ of rain per hour. It made it necessary to increase the pumping station with the installation of a new electric pump, with characteristics identical to the group already in operation.

\section{Subirrigation system}

During the 43 years of operation of the sprinkler irrigation it was necessary to some make financial statements that put emphasis on water consumption, increased over the years, and the ever-declining production. Over time, the crops were constantly subjected to pruning, sometimes drastic, and grafts, aimed at maintaining the crop in good health and production.

The crop, consequently to the reduction water supplied, has suffered a lot, especially in years of severe drought such as 2003 and with the passage of time, yields have declined a lot. Therefore, in 2008 the possibility to make a change was taken into consideration to prevent the situation from getting worse. In order to reduce production costs, in particular those related to water supply and consumption of electricity, and to increase yields, the sprinkler plant was replaced with a more modern subirrigation system. The plant is divided into four sectors of 1.6 ha (Figure 2); water comes through pipes with a diameter of $110 \mathrm{~mm}$. The driplines have a diameter of $16 \mathrm{~mm}$.

A distribution network is created that makes possible to explant and replant crops in different position without compromising the water supply. The pipes depth varies along the different areas of the plot. In places where there is the transit of agricultural means the driplines are placed at a depth of about $40 \mathrm{~cm}$ to 


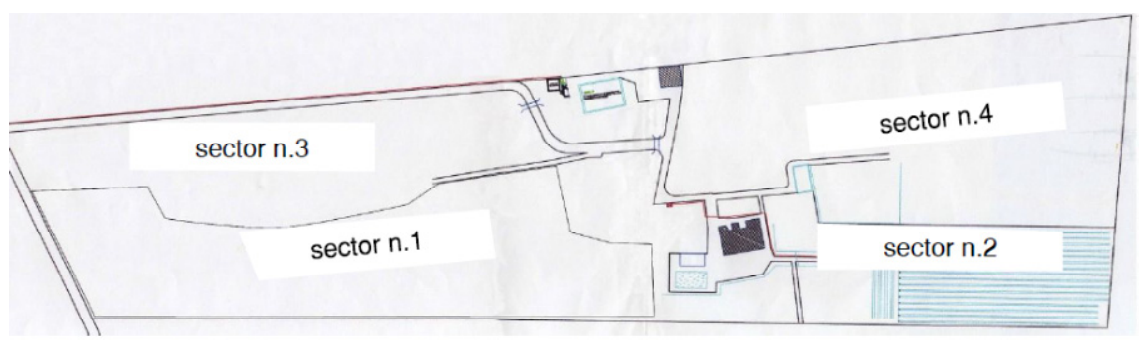

Figure 2: $\quad$ Drip irrigation scheme.

prevent the direct crushing. The high stoniness of the soil makes impossible to operate at high-depth and moreover the possibility of intervention in case of problems is to take into account. Both factors have determined the laying at a depth of about $10-15 \mathrm{~cm}$. The project includes a water supply for a single tree of about 280 liters a week, corresponding to an average number of emitters equal to 11 , as the water flow for a single emitter is $2.1 \mathrm{l} \mathrm{h}^{-1}$ and running period is of 12 hours a week.

In the phase of gathering data for comparing the installations, 8 sample plants have been identified, 2 for each sector, for which the actual water supply was analyzed. The drippers surrounding the plant were first unearthed, later a circle with a radius of 1.5 meters was traced around the trunk and within the number of emitters was counted and the respective distance was measured. The driplines have a diameter of $16 \mathrm{~mm}$ with drippers every $50 \mathrm{~cm}$ (Figure 3).

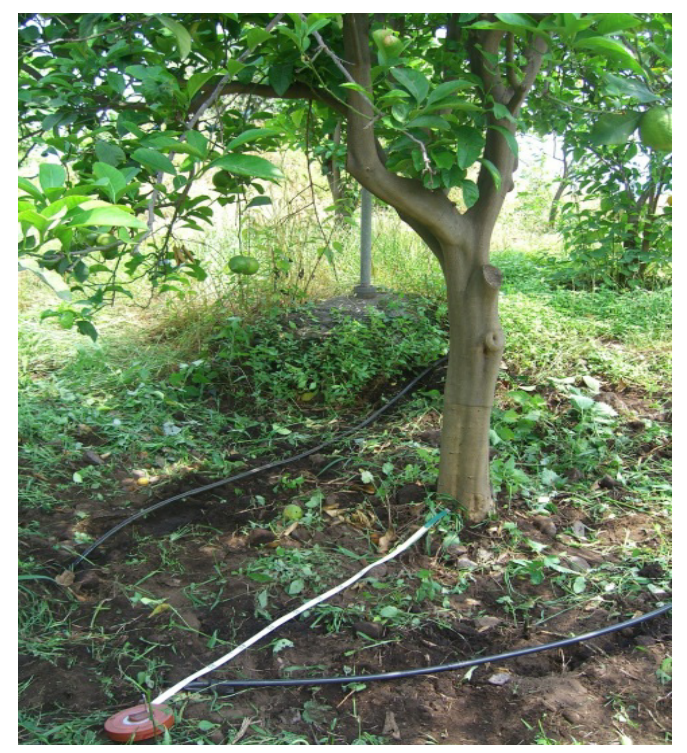

Figure 3: Drip irrigation installation. 
At the end of the irrigation season a water balance was conducted and cost of the new facilities were evaluated in order to compare the costs of water supply and distribution volumes of the two different systems in the years 2008 and 2009. The results are reproduced in Table 1.

Table 1: $\quad$ Comparison between sprinkler and drip irrigation performances.

\begin{tabular}{|c|c|c|}
\hline & Sprinkler irrigation & Sub-irrigation \\
\hline year & 2008 & 2009 \\
\hline $\begin{array}{c}\text { flow rate per each sector } \\
(1 / \mathrm{s})\end{array}$ & 6.6 & 6.0 \\
\hline $\begin{array}{c}\text { irrigation time } \\
\text { (hour/month) }\end{array}$ & 230 & 192 \\
\hline $\begin{array}{c}\text { monthly water volume } \\
(\text { mc/month) }\end{array}$ & 5,500 & 4,150 \\
\hline $\begin{array}{c}\text { seasonal water volume } \\
(\mathrm{mc} / \text { hectar) }\end{array}$ & 4,230 & 3,190 \\
\hline water cost $(€ /$ mc) & 0.36 & 0.37 \\
\hline total irrigation cost $(€)$ & 9,900 & 7,700 \\
\hline
\end{tabular}

\section{Conclusion}

The installation of the subsurface irrigation has led to significant changes at company level both from the structural point of view, and with respect to the use of water resources. The water use efficiency is certainly improved if compared to sprinkler irrigation.

The high consumption due to water supply over the entire surface, including walls and streets, as well as the areas occupied by weeds, were practically canceled. The plants must adapt to the new distribution method, and this takes time. However, after the first season with subsurface irrigation, a better physiological state of the crop is observed.

The next few years will provide more evidence and an assessment can be made on the basis of data on the actual yield. After about six months the water consumption and the related costs have significantly decreased. Comparing the used volumes and the costs of water supply for the years 2008 and 2009 a $25 \%$ decrease of the water supplied to the crop during the irrigation season has been observed and a $23 \%$ decrease in respect of the cost of resource. 


\section{References}

[1] Castel, J.R., Bautista, I., Ramos, C. and Cruz, G., Evapotranspiration and irrigation efficiency of mature orange orchards in Valencia (Spain). Irrig. Drain. Syst., (3), pp. 205-217, 1987.

[2] Catoni, A., Guida pratica dell'irrigazione a pioggia, Edagricole: Bologna, 1968.

[3] Hoffman, G.J., Oster, J.D. and Alves, W.J., Evapotranspiration of mature orange trees in an arid climate. Summer meeting of the Amer. Soc. Of Agric. Eng., San Antonio, Texas, June 15-18, 1980. 